\title{
SJoP
}

\section{Afterword: Acts of care}

\section{LAURA BISSELL, LAURA GONZÁLEZ, DEE HEDDON \& SIMON MURRAY}

The Scottish Journal of Performance

Volume 5, Issue 1; April 2018

ISSN: 2054-1953 (Print) / ISSN: 2054-1961 (Online)

Publication details: http://www.scottishjournalofperformance.org

To cite this article: Bissell, L., González, L., Heddon, D., and Murray, S., 2018. Afterword: Acts of care. Scottish Journal of Performance, 5(1): pp. 179-184.

To link to this article: http://doi.org/10.14439/sjop.2018.0501.17

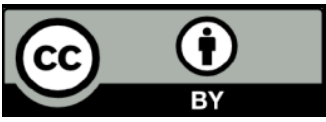

This work is licensed under a Creative Commons

Attribution 4.0 International License. See

http://creativecommons.org/licenses/by/4.0/ for details. 
AFTERWORD:

\section{Acts of care}

LAURA BISSELL, LAURA GONZÁLEZ, DEE HEDDON \& SIMON MURRAY

DOI: 10.14439/sjop.2018.0501.17

Publication date: 6 April 2018

It began with the question of care, but soon enough more practical ones took over: how to organise a symposium in under three months, using standard university spaces, with next to no money while still practising care?

This is the challenge we set ourselves with The Art of Carefull Practice, held on Sunday 5 March 2017 at Gilmorehill Halls, University of Glasgow, as part of the inaugural Take Me Somewhere festival. Jackie Wylie, now Artistic Director of the National Theatre of Scotland, conceived this Glasgowwide festival of contemporary performance as a small act of repair following the closure of The Arches on 9 June 2015. The Arches was the working home of many Glasgow-based performance-makers and live artists, including Adrian Howells and Ian Smith, both of whom took their lives in 2014. The symposium, ghosted by their presence, work and practices, was a way of attempting to understand our losses and shaped how we began to understand care. It is this context that helped us focus on our task, despite all the challenges.

Identifying the key principles of the event, we established at the outset that a necessary condition for care, in the way we wanted to explore it, was intimacy. We chose to keep the event small with a maximum of 50 people in attendance which we hoped would enable us to attend to everyone present, to really see them, and provide the opportunity for 
everyone to feel part of a discussion. The design of our event responded to our experiences of symposia where the aim is to make money, or to meet imperatives set by funders, or to be a blatant cover for something else (including recruitment and networking). By contrast, we wanted to construct a careful, stimulating and creative environment for the people who gave up their Sunday to join us in thinking through what a care-full practice might be. To support access, the event was free of charge. We asked participants to apply, explaining how care is valued and voiced in their work. We wanted dialogue to be at the heart of the event, which would require a collective engagement and commitment to exploring care. We also fulfilled our role as care-full organisers by giving careful attention to those given more formal time and space to present at the event, ensuring a diversity of speakers, practices and experiences. Many of them are represented in this journal. We thank them warmly for their diligence, their interest and their generosity.

At registration, each participant was given a sticker (colourcoded with ten different groups), and one of five 'care-full' drawings: a hand, a heart, a tree, a cup of tea and an ear (for listening). These were conceptualised and hand-made by Laura González. The colours and symbols were designed to encourage unexpected encounters and to foster new, surprising connections and conversations. After starting the day together and setting off with a series of short provocations intended to prompt our thinking about 'care', participants separated into rooms assigned according to their symbols. Their discussion of care was 'held' around the carefully designed architecture of the Long Table (as devised by Lois Weaver and discussed in this journal). Operating as a horizontal space of dialogue without hierarchy, the long table provided everyone present with the space to share thoughts, questions and experiences, responding to the initial provocations. Contributions could be made verbally and / or in writing. As prompts to 
reflection and discussion, we asked:

- How do we ensure the practice of working with nonprofessional participants in the processes and production of performance is ethical?

- How do we care for the other(s) in work that might be difficult, challenging, demanding?

- How do we care for the self in work that requires complex configuration of aesthetics, relations and responsibilities?

Our participants asked, in turn:

- How do you allow for disagreement and divergence of opinion while still performing a culture of care?

- How do we deal with loss productively in this fragile ecosystem of artists, makers, producers and academics?

- When is a provocative act generative and when is it destructive?

- Where and how do we set boundaries?

- How do we take care of ourselves?

- How can it all be allowed? 
The very act of asking, questioning and acknowledging the multiple issues in making, seeing and discussing performance work, seemed to be an act of care.

If we were keen to avoid typical symposia structures, we were equally keen to avoid the typical university lunch (curling sandwiches filled with cheese savoury or coronation chicken). With limited resources, how could we provide sustenance? Food and feeding are so intimately connected to care. The answer for us was simple: sometimes, the best way to practise care is to ask participants to share in its practice, so we invited everyone to bring a contribution to a collective salad-lunch. One of our most vivid memories of the day was the queue to register: people clutching bowls, plates and platters of delicious home-cooked food, healthy roast vegetables and favourite recipes. This was a communal lunch made with love. We also asked participants to bring a gift to be exchanged with someone over lunch: something that represented 'care', however subjective. We saw the gift as providing a doorway to interacting with people we had just met that day, had not seen for a while, or who were complete strangers. The gift offered a means of telling and exchanging stories of care.

We set lunch up in the long, glass-fronted, functional corridors of Gilmorehill. Rather like a train carriage, the tables became loci of convivial conversation and culinary laboratories of care. While still retaining the intimacy of the event, there was a chaotic energy of togetherness, culminating in a spontaneous, joyful rendition of Happy Birthday sung for one of our participants-strangers and friends joining together as a chorus.

We had moved from the architecture of the long table, to two long corridors of tables accommodating four. The careful format of the former offered important, sympathetic preparation for the practice of making and sharing the 
lunch in these smaller gatherings. This lunchtime intimacy was in turn a necessary preparation for the afternoon, which required different registers of listening, attention and response. We were invited to view Quarantine's Winter. (written about in this journal) and video documentation of Adrian Howells' live performances (to whom this journal is dedicated), and witness Nic Green's process through her sharing of an early work in progress. As the first recipient of the Adrian Howells Award for Intimate Practice, Green offered a choral performance exploring grief through song.

Mindful of the difficult politics of the plenary session, a form not always inclusive and sensitive to the participants at the end of a long day, we did nevertheless recognise the value of coming together to draw some provisional conclusions. Throughout the day, three people undertook the role of 'listeners'; they could move fluidly between the sessions and groups, with the aim of offering their own accounts of the event. The observations of these listeners were presented in the final session, along with the invitation for attendees to share their experience of The Art of Care-full Practice through this special issue of the Scottish Journal of Performance.

In the spirit of symposium, we ended the day with more food (this time prepared by the nearby restaurant, The Left Bank) and more intimate and convivial conversation, celebrating all we had seen, heard, thought and shared, continuing our dialogue and care for each other into the night.

Through the organisation of this event, we learned that care has agency-it doesn't count if there is no act; doing nothing is not an option. Care needs action, however small or subtle that might be. The food, the gift, the long table, the listening, the seeing, the work, the space and the time, all these reflected our desire to create an event that was neither 
overly-busy nor tiring. We wanted the day to breathe, and for conversations to develop naturally over that Sunday and, beyond, in and through this journal. For this reason, we will not overstay our welcome. We just wanted to conclude with where it all began: with the idea that if we care, perhaps things can turn out differently. 